\title{
Intestinal microbial metabolites in human metabolism and type 2 diabetes
}

\author{
Hilde Herrema $^{1}$ (D) Jan Hendrik Niess ${ }^{2,3}$ (D \\ Received: 17 April 2020 / Accepted: 13 July 2020 / Published online: 3 September 2020 \\ (C) The Author(s) 2020
}

\begin{abstract}
Humans with the metabolic syndrome and type 2 diabetes have an altered gut microbiome. Emerging evidence indicates that it is not only the microorganisms and their structural components, but also their metabolites that influences the host and contributes to the development of the metabolic syndrome and type 2 diabetes. Here, we discuss some of the mechanisms underlying how microbial metabolites are recognised by the host or are further processed endogenously in the context of type 2 diabetes. We discuss the possibility that gut-derived microbial metabolites fuel the development of the metabolic syndrome and type 2 diabetes.
\end{abstract}

Keywords Intestinal barrier $\cdot$ Metabolites $\cdot$ Microbiome $\cdot$ Review $\cdot$ The metabolic syndrome $\cdot$ Type 2 diabetes

$\begin{array}{ll}\text { Abbreviations } \\ \text { AhR } & \text { Aryl hydrocarbon receptor } \\ \text { BCAA } & \text { Branched-chain amino acid } \\ \text { CLA } & \text { Conjugated linoleic acid } \\ \text { FFAR } & \text { Free fatty acid receptor } \\ \text { FMT } & \text { Faecal microbiota transplantation } \\ \text { FXR } & \text { Farnesoid X receptor } \\ \text { GABA } & \gamma \text {-Aminobutyric acid } \\ \text { GLP-1 } & \text { Glucagon-like peptide 1 } \\ \text { GPCR } & \text { G protein-coupled receptor } \\ \text { ILC } & \text { Innate lymphoid cell } \\ \text { ImP } & \text { Imidazole propionate }\end{array}$

Electronic supplementary material The online version of this article (https://doi.org/10.1007/s00125-020-05268-4) contains a slide of the figure for download, which is available to authorised users.

Hilde Herrema

h.j.herrema@amsterdamumc.nl

$\triangle$ Jan Hendrik Niess

janhendrik.niess@unibas.ch

1 Department of Experimental Vascular Medicine, Amsterdam University Medical Centers, Location AMC, Meibergdreef 9, 1105 AZ Amsterdam, the Netherlands

2 Department of Biomedicine, University of Basel, Hebelstrasse 20, CH-4031 Basel, Switzerland

3 University Center for Gastrointestinal and Liver Diseases, St Clara Hospital and University Hospital of Basel, Basel, Switzerland
LCFA Long-chain fatty acid

LPS Lipopolysaccharide

NASH Non-alcoholic steatohepatitis

PYY Peptide YY

SCFA Short-chain fatty acid

TMA Trimethylamine

TMAO Trimethylamineoxide

UDCA Ursodeoxycholic acid

VIP Vasoactive intestinal peptide

\section{Introduction}

The gut microbiome in humans can be considered as an organ, which has functions critical for human metabolism, digestion, maintenance of gut barrier function and immunomodulation. Moreover, the gut microbiome has been linked to many diseases not classically associated with microbes, such as metabolic diseases, rheumatoid arthritis and psychiatric disorders. A skyrocketing number of publications implicate the gut microbiome in the development of metabolic diseases including obesity and type 2 diabetes. Although the majority of publications on human disease development are associative and, as yet, do not provide much mechanistic insight, the field is rapidly moving towards translational studies combining animal models with human intervention. This movement is 
critical to push forward our understanding of this complex community in the regulation of human metabolism.

The gut microbiome has emerged as a targetable organ with potential to alter disease development. This is important in light of the ever-increasing global prevalence of type 2 diabetes [1], which still has an unresolved clinical need for prevention and cure. This debilitating disease has high morbidity and mortality rates and is estimated to affect 700 million people by 2045 [2], with certain ethnicities being overrepresented [3-5]. Type 2 diabetes is characterised by deficient insulin secretion from the pancreatic beta cells coinciding with impaired insulin sensitivity of tissues and organs with a major role in glucose clearance (adipose tissue, liver, muscle). Many gene variants have been linked to type 2 diabetes risk [6]; these variants have been estimated to increase risk by $10-30 \%[7,8]$. In the vast majority of cases, however, type 2 diabetes is driven and preceded by the metabolic syndrome, a cluster of interconnected lifestyle-related clinical features that consist of elevated fasting glucose, increased BP, reduced HDL-cholesterol, increased circulating triacylglycerols and obesity. Although obesity is a critical (and noticeable) hallmark of the metabolic syndrome, other clinical features often exist unnoticed or are not present at all. The metabolic syndrome is, thus, often not recognised, making it difficult to calculate its exact global prevalence. Estimates suggest that the metabolic syndrome is three times more prevalent than type 2 diabetes [9]; this translates into 1 billion people worldwide being affected by this condition and, hence, being at risk of developing type 2 diabetes.

In addition to the metabolic syndrome being a critical risk factor for type 2 diabetes, the gut microbiome has been extensively linked with the metabolic syndrome and type 2 diabetes in humans. Although a commonly carried dogma in the field is that the gut microbiome of individuals with type 2 diabetes (or with the metabolic syndrome preceding it) is characterised by lower diversity [10-12], there are many publications that cannot confirm these data [13] (see 'Altered microbiome composition in type 2 diabetes' section, below).

Importantly, mouse studies [14-16] and human intervention studies [17-19] in which the gut microbiome composition is modified (e.g. by faecal microbiota transplantation [FMT]) indicate a causal role for the gut microbiome in type 2 diabetes development. Moreover, these studies imply that targeting the gut microbiome holds merit to serve as a preventive measure for type 2 diabetes development or to lower the burden on those already affected.

We would like to emphasise that the vast majority of research on the role of the gut microbiome in type 2 diabetes development is focused largely on bacteria. The gut microbiome, however, is a spectacularly complex community of microorganisms, including bacteria, fungi, protozoa and viruses (mainly bacteriophages), which, as a whole, has been implicated in the development of several human diseases.
However, little is known about community-level dynamics and local interaction between members of these different kingdoms of life. This is beyond the scope of this review but anticipated by the authors to be critical for our understanding of how the gut microbiome alters human disease development and for development of microbiome-targeted interventions.

With the exception of pathogenic infections or specific diseases that alter intestinal barrier function, the microbial community is generally considered to be confined to the intestine. Nevertheless, the microbiome exerts metabolic actions on most distal tissues and organs in the human body (Fig. 1). These actions are mediated by local interaction of the microbiome or microbial metabolites with immune cells, enteroendocrine cells or cells of the central nervous system. Moreover, penetrance of microbial metabolites to distal body sites has been implicated in (dys)regulation of tissue metabolic pathways. We will, in this review, focus on how microbial metabolites influence metabolic pathways relevant to type 2 diabetes development.

\section{Altered microbiome composition in type 2 diabetes}

Several diseases are associated with a microbiome composition that is different from that in health. Although a strong definition of a healthy microbiome is lacking, the microbiome of a diseased population is generally termed 'dysbiotic'. It must be noted, however, that the term 'dysbiosis' also lacks a clear definition and that 'altered microbiome composition' may be a more suitable term. In obesity and type 2 diabetes, microbiome composition may be altered to include overrepresentation of microorganisms (often opportunistic pathogens) that are lacking in the healthy population and reduced individual species diversity (alpha diversity). However, findings from published studies are, in part, contradictory regarding microbiome composition in individuals with type 2 diabetes, as nicely reviewed by Gurung and colleagues [20]. Since microbiome composition is regulated by many factors (in particular diet, medication use, environment and host genetic makeup), it can be challenging to determine whether the altered microbiome composition observed is a cause or consequence of a disease. As an example, metformin, an abundantly prescribed therapy for type 2 diabetes, is known to have a major impact on microbiome composition and function [21]. It is therefore of critical importance to correct for treatment regimens when studying the impact of the gut microbiome on human disease development. Moreover, because interindividual differences are large (not only in disease but also in the healthy population), it is difficult to define a health- or diseaseassociated microbiome (or characteristics thereof) and to reproduce findings between research groups. On a population level, large numbers $(N>1500)$ are needed to confidently 


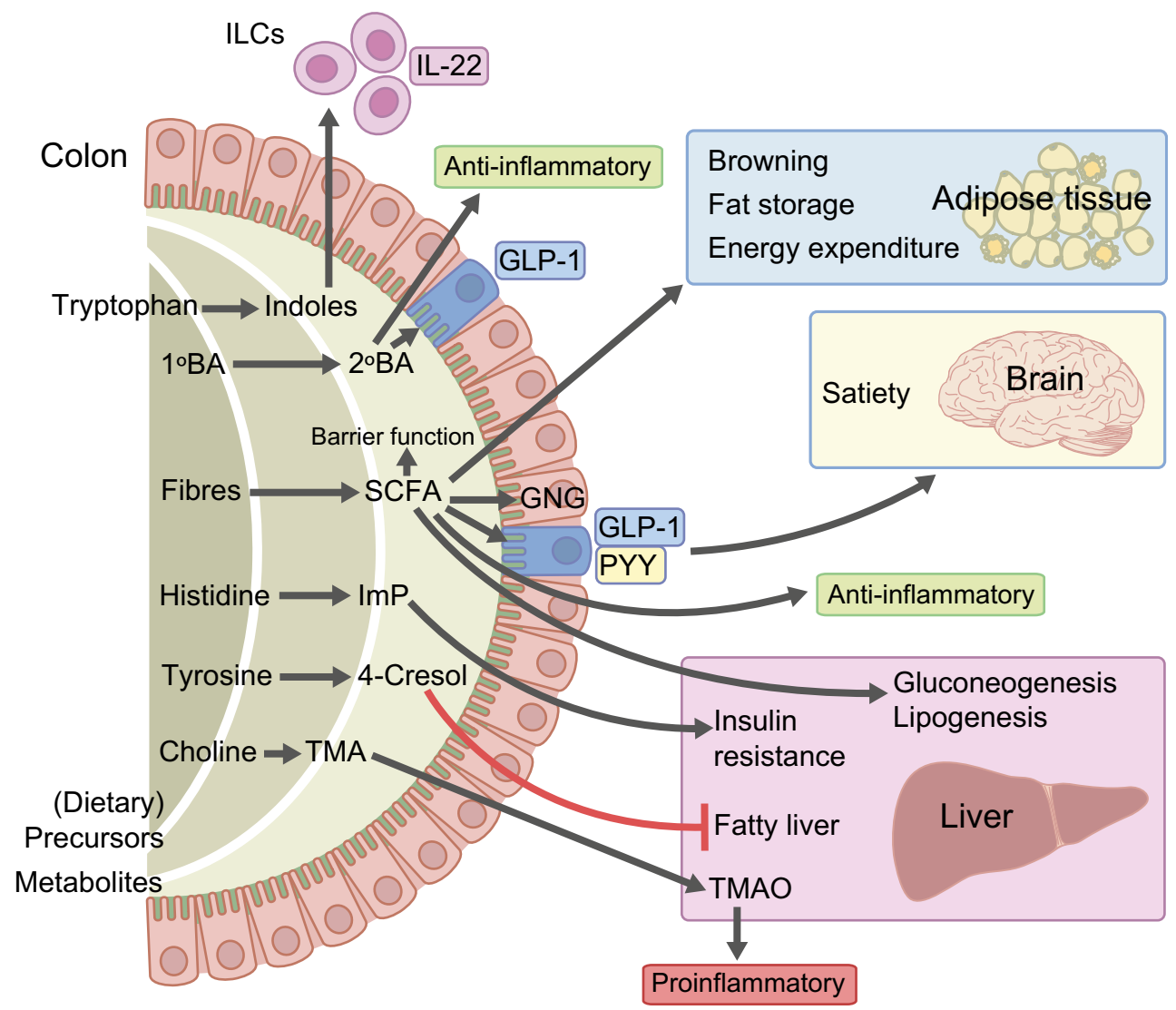

Fig. 1 Gut-derived microbial metabolites influence host responses in the context of the metabolic syndrome and type 2 diabetes. For example, intestinal microbes metabolise diet-derived tryptophan to indoles, which in turn induce IL-22 production by ILCs [84]. In addition, primary bile acids $\left(1^{\circ} \mathrm{BAs}\right)$ are converted to secondary bile acids $\left(2^{\circ} \mathrm{BAs}\right)$ by the microbiome. Converted $2^{\circ} \mathrm{BAs}$ are involved in anti-inflammatory pathways [110]. Fibres are processed into SCFAs, which facilitate browning of fat tissues, fat storage and energy expenditure in adipose tissue, satiety regulation in the brain via regulation of PYY and GLP-1 in gut neuroendocrine cells [75], and anti-inflammatory pathways in the immune system. Moreover, the SCFA butyrate is the main energy source of

identify microbiome 'signals' associated with variables of obesity or type 2 diabetes.

In early publications, the obesity-associated microbiome was postulated to extract more energy from dietary components when compared with healthy microbiome $[15,22]$. Although some of these findings have been difficult to reproduce in other studies [23-26], several observations have been consistently and reproducibly reported. For example, proinflammatory bacteria (e.g. Escherichia coli) have been shown to be more abundant in type 2 diabetes [27-29]. These bacteria carry immunoreactive lipopolysaccharide (LPS) on their cell walls and are hence considered a trigger for the lowgrade inflammation associated with type 2 diabetes [30-32].

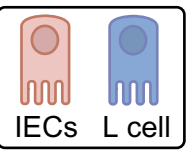

intestinal epithelial cells. Thereby, SCFAs help to maintain the integrity of the intestinal barrier. In addition, SCFAs promote gluconeogensis and lipogenesis in the liver. The microbiome also metabolises histidine to ImP, tyrosine to 4-cresol, and choline to TMA. ImP inhibits insulin receptor substrate signalling in the liver, and 4-cresol prevents hyperglycaemia and fatty liver in mice [98]. Meanwhile, TMA is further converted by endogenously expressed hepatic flavine-containing monooxygenase 3 into TMAO. TMAO has been implicated in inflammatory pathways relevant for the development of type 2 diabetes and for cardiovascular diseases [90]. GNG, gluconeogenesis; IEC, intestinal epithelial cells. This figure is available as a downloadable slide

Bacteria considered to have anti-inflammatory properties (e.g. Fecalibacterium prausnitzii), on the other hand, are generally underrepresented in the microbiome of obese humans and those with type 2 diabetes [27-29]. These anti-inflammatory properties are, in part, deduced from the capacity of these bacteria to produce the heavily studied short-chain fatty acid (SCFA) metabolites. SCFAs (primarily acetate, propionate and butyrate, which are present in the colonic lumen in a molar ratio of 3:1:1) are produced, on a large scale, from the microbial fermentation of fibres, a process estimated to provide $5-10 \%$ of our daily energy. Locally, intestinal epithelial cells have been estimated to derive $70 \%$ of their energy from butyrate, which is mainly produced by bacteria with 
proposed beneficial effects for host metabolism (e.g. Ruminococcus and Faecalibacterium) in mice [33]. It is important to mention, however, that the vast majority of potentially pathogenic bacteria also have the machinery to produce SCFAs [34]. Whether or not this translates into actual use of this capacity (i.e. leading to SCFA production) depends on substrate availability and local circumstances. Moreover, certain strains might have increased response to substrates when compared with close relatives, as shown for Bifidobacterium pseudocatenulatum [21]. Interestingly, although SCFA producers have been reported to be relatively depleted in obesity and type 2 diabetes, SCFA levels have been reported to be increased in a diet-dependent fashion [26, 35-37]. Deficient SCFA handling in type 2 diabetes has been postulated but this hypothesis remains to be confirmed. This path is likely paved with challenges as SCFA turnover is difficult to assess due to the above-mentioned utilisation of SCFA by intestinal cells as well as bacteria. In the vast majority of studies, a snapshot of the SCFA levels at a defined moment in time is provided. Such data are unsuitable readouts for SCFA metabolism.

\section{The intestine as a critical firewall for microbial metabolite production, passage and signalling}

The microbiome of the gastrointestinal tract develops when a baby's immune system is exposed to microorganisms, fungi and viruses after birth [38]. This community stabilises around 1 year after birth, after weaning and when a regular diet has been introduced [39]. From the beginning of life, an intimate relationship between the host and the microbiome develops [40]. The microbiome and host have a two-way relationship in which the host provides an ecological niche for the microorganisms, and the microbiome supports the host in digestion and uptake of vitamins [41, 42], bile acids and amino acids [43], development of the immune system [44, 45] and in protection from invading pathogens [46]. Functional metagenomics, an experimental approach to study the function of encoded proteins, may be used to identify bacterial effector genes and gene products from the gut microbiome that mimic endogenously produced metabolites by the host. For example, microbial commendamide (an $\mathrm{N}$-acyl-3hydroxyglycine) resembles endogenously produced $N$-acylamide signalling molecules. Thereby, $\mathrm{N}$-acyl-3hydroxyglycines signal through the $G$ protein-coupled receptor (GPCR) G2A/132 and suppress proinflammatory immune responses [47]. To avoid unwanted inflammatory responses to the symbiotic microorganism, the host has developed strategies to reduce contact between the immune system and microorganisms [48]. These firewalls include the mucous separating the microorganism from the epithelial layer sealed by tight junctions [49], production of antimicrobial peptides by Paneth cells [50], macrophages located beneath the epithelium to ingest and destroy breaching (pathogenic) bacteria [51], and production of IgA [52]. IgA facilitates immune exclusion, a host defence system that prevents interaction of antigens with epithelial cells, by attenuation of bacterial motility, growth and adhesion to epithelial cells [53]. It also facilitates immune inclusion by promoting the growth of beneficial bacteria while inhibiting potential harmful competitors of these beneficial bacteria in the same niche $[52,54]$. In rare circumstances, after breakdown of these firewalls, symbiotic microorganisms disseminate through blood vessels or the portal vein and are killed by macrophages in the spleen and Kupffer cells in the liver. Individuals with liver cirrhosis as a possible consequence of non-alcoholic fatty liver disease (NAFLD) exhibit impaired clearance of disseminated microbes in the liver and, thereby, have a high risk of developing systemic infections [55]. In humans with the metabolic syndrome, altered microbiome composition together with a defective intestinal barrier has been suggested to facilitate translocation of microbes, thereby contributing to low-grade inflammation. Although bacterial DNA has indeed been reported in circulation and tissues of people with type 2 diabetes, the extent to which living bacteria translocate from the gut to other body sites in humans is the topic of extensive debate [56, 57]. Since technical challenges currently do not allow us to fully clarify this question, the concept of bacterial translocation remains controversial.

Bacteria-derived metabolites, often with hormone-like activity, are more likely to disseminate into the circulation [58]. LPS, a cell-wall component of Gram-negative bacteria, and flagellin, a structural component of the bacterial locomotor appendage flagellum, are particularly recognised for their immunomodulatory properties. LPS levels are increased in humans with type 2 diabetes and in mouse models of the metabolic syndrome, a phenomenon known as metabolic endotoxaemia [31, 32]. In addition, administration of LPS was found to reduce glucose tolerance and glucosestimulated insulin secretion in mice, in which activation of inflammatory pathways is considered a central mechanism in the development of the disease phenotype. LPS and flagellin are recognised by Toll-like receptors 4 and 5, respectively. These pattern-recognition receptors are mainly expressed on epithelial cells and cells of the innate immune system and play critical roles in activation of the immune response.

\section{Gut microbe-derived metabolites}

In addition to microbes or their structural components, intestinal microbial metabolites also enter the host; approximately $10 \%$ of all metabolites in the blood of mice stems from the microbiome [59]. High-throughput metabolomics strategies 
comprising mass spectrometry coupled with gas- or liquidphase chromatography and nuclear magnetic resonance spectroscopy provide a snapshot of the metabolome in people with type 2 diabetes. These strategies have revealed novel associations between microbial or endogenous metabolites (most notably sugars, lipids and amino acids) and variables of type 2 diabetes or the metabolic syndrome that precedes it [60]. Insulin resistance and risk of developing type 2 diabetes have been strongly associated with branched-chain amino acids (BCAAs) and aromatic amino acids, respectively. In addition, levels of gluconeogenic precursors and lipids, such as sphingomyelins, triacylglycerols and palmitate, are generally increased in people at risk of developing type 2 diabetes. Mechanistically, amino acids directly impair insulin signalling in skeletal muscle and reduce glucose uptake. BCAAs have been implicated in short- and long-term regulation of insulin secretion by pancreatic beta cells and are reported to prohibit beta cell function by inducing hypersecretion, an important hallmark of type 2 diabetes [61, 62].

Although metabolites are small intermediate- or endproducts of chemical processes that keep cells alive, it is important to note that the fairly high rate of bacterial cell death in the intestine also contributes to the metabolite load $[63,64]$. Gut microbial metabolites mostly stem from dietary components fermented by bacteria, such as SCFAs (mainly butyrate, acetate, propionate), unsaturated and saturated medium- and long-chain fatty acids (LCFAs), and tryptophan metabolites. Microorganisms also modify endogenous metabolites, such as bile acids, intermediates of the citric acid cycle and cholesterol metabolites, and bacteria can de novo synthesise metabolites, such as adenosine triphosphate. The penetration of host tissues by these gut microbial metabolites is classically demonstrated by comparing metabolite profiles of germ-free rodents (which lack microbiome) with metabolite profiles of conventional rodents [65-67]. When using this approach, it is assumed that metabolites that are absent in germ-free rodents are derived from the microbiome; however, this approach does not distinguish between metabolites that can be produced by both the microbiome and the host. More importantly, differences between the concentrations of these 'overlapping' metabolites in germ-free and control rodents might be owing to the fact that the absence of microbiome is likely to alter endogenous metabolite production in germ-free animals. Uchimura and co-workers used an elegant approach to show metabolite penetration into tissues of germ-free mice [68]. To this end, mice were treated with $E$. coli labelled with ${ }^{13} \mathrm{C}$ (which makes up only $1.1 \%$ of all naturally occurring carbon), which generate ${ }^{13} \mathrm{C}$-labelled metabolites. In contrast, all metabolites produced by the mouse are ${ }^{12} \mathrm{C}$, which accounts for approximately $99 \%$ of natural carbon. ${ }^{13} \mathrm{C}$-labelled E. coli-derived metabolites could hence be discriminated from ${ }^{12} \mathrm{C}$ mouse metabolites. Bacterial amino acids penetrated almost all organs assessed, whereas bacterial lipids mainly appeared in the intestinal regions. The proximal small intestine was the main site for microbial metabolite uptake.

Of importance, there is limited information on smallintestinal microbial metabolite metabolism in humans. Only one study has been reported in participants with the metabolic syndrome; these individuals were receiving an FMT and duodenal biopsies were collected [17]. This may be because the upper part of the small intestine, the duodenum, can only be accessed by oesophagogastroduodenoscopy, which allows the inspection of the first portion of the small intestine (duodenum). The distal part of the small intestine, the terminal ileum, can only be accessed by ileocolonoscopy. Ileocolonoscopy requires colon cleansing, which tremendously affects the composition of the microbiome and probably the metabolome produced by the gut microbiome. The 3 to $5 \mathrm{~m}$ between the duodenum and the terminal ileum (the jejunum) are not accessible by oesophagogastroduodenoscopy or ileocolonoscopy and are, hence, understudied.

Intestinal barrier function (e.g. mucus and IgA production) is mainly matured by the gut microbiome [69]; hence, germfree mice have deficient gut barrier function. To correct for this in one study, germ-free mice were transiently colonised to mature the gut barrier [70]. To address the role of immunoglobulins in gut barrier function, microbial metabolite penetration was compared in transiently colonised germ-free wildtype mice and Igh-J-knockout mice, which lacked all antibody isotypes ( $\operatorname{IgA}, \operatorname{IgG}, \operatorname{IgM}, \operatorname{IgD})$. Microbial metabolite levels were higher in the distal intestinal contents of conditioned wild-type mice when compared with conditioned Igh-Jknockout mice. In line with the hypothesis that $\operatorname{IgA}$ reduces the dwell time of bacteria and their metabolites in the small intestine, there was greater uptake of metabolites in the small intestine of $I g h-J$-knockout mice and unconditioned germ-free mice compared with conditioned germ-free mice. Of importance, increased exposure of host organs to microbial metabolites enhanced activation of the immune system. Increased low-grade inflammation, potentially via the gut microbiome, is an event strongly related to diabetes development [30-32]. Thereby, the induction of IgA facilitates the transit of intestinal bacteria from the small intestine into the colon. Bacterial metabolites penetrate into the host mainly in the small and not large intestine. Thereby, the transit of bacteria into the colons prevents excessive accumulation of bacterial metabolites in the host.

\section{Gut microbe-derived metabolites alter endogenous metabolism}

Metabolite-sensing receptors After their penetration into the host, microbial metabolites are further processed by endogenous enzymes. Although GPCRs have been described to directly recognise bacterial metabolites in host tissues [71, 
72], the majority of 'metabolite-sensing receptors' are yet to be identified (Table 1). Examples of metabolite-sensing receptors include the SCFA receptors GPR41 (free fatty acid receptor [FFAR]3), GPR43 (FFAR2) and GPR109A (niacin receptor 1 [NACR1]) that mediate a wide range of effects on host metabolism. These receptors, both separately and in concert, have been implicated in the regulation of satiety [73], browning of white adipose tissue and fat accumulation [74], glucagon-like peptide 1 (GLP-1) secretion [75], intestinal gluconeogenesis and peptide YY (PYY) secretion [76]. SCFAs also inhibit the activity of histone deacetylase, leading to histone hyperacetylation, by which the expression of approximately $2 \%$ of all mammalian genes are repressed [77]. Multiple receptors bind SCFAs and a given SCFA may bind to several receptors. In addition to their signalling properties, SCFAs have been shown to serve as gluconeogenic and cholesterogenic precursors in mice [78] and lean humans [79] thereby also serving a quantitative role as catabolic or anabolic substrates. Basic and clinical studies are required to dissect this system further before therapies targeting the SCFA receptors can be developed.

Another metabolite-sensing receptor, the transcription factor aryl hydrocarbon receptor (AhR), senses xenobiotic chemicals, such as aromatic aryl hydrocarbons [80]. Recent work suggests that the AhR also recognises derivatives of the essential aromatic amino acid tryptophan [81]. Two endogenous pathways (the kynurenine and serotonin pathways) and one microbe-dependent pathway (the indole pathway) are involved in the metabolism of diet-derived tryptophan. In the kynurenine pathway, tryptophan is metabolised to kynurenine and kynurenic acid, while in the serotonin pathway, tryptophan is metabolised to the neurotransmitter serotonin. In the indole pathway, gut-resident microbes use tryptophan as a nitrogen source and, thereby, also produce indoles, which bind to the AhR [82]. The AhR facilitates several functions in the gastrointestinal tract, such as regulation of peristalsis and motility [83] and induction of IL-22 production by T cells and innate lymphoid cells (ILCs) [84]. Interestingly, in mice, IL-22 production by ILCs can be inhibited by vasoactive intestinal peptide (VIP)-expressing enteric neurons, thereby linking the immune and nervous systems in the gut [85]. As food consumption elicits VIP production by neurons, these $\mathrm{VIP}^{+}$ neurons inhibit IL-22 production by ILCs during food intake, which is associated with reduced production of antimicrobial peptides and with overgrowth of potentially pathogenic bacteria, such as segmented filamentous bacteria in mice. In contrast, feeding induces expression of lipid-binding proteins and transporters. Thus, the recognition of tryptophan-derived metabolites by AhRs regulates gut motility, pathobiont overgrowth and lipid uptake by inhibition of IL-22 production through VIP-expressing enteric neurons during nutrient uptake [85].

Many bacteria are also capable of producing mammalian neurotransmitters, such as dopamine, noradrenaline (norepinephrine), serotonin or $\gamma$-aminobutyric acid (GABA) [86]. Although it remains to be shown whether microbial production of some of these neurotransmitters indeed alter endogenous metabolism, some have been shown to activate the gut-brain axis and have been implicated in the modulation of endogenous metabolism. GABA, for example, has long been known to be produced by the gut microbiome, including members of the Bifidobacterium and Lactobacillus genera [87]. It has been implicated in glucose homeostasis and has been shown to improve beta cell function [88, 89]. Of interest, GABA was the most altered metabolite in obese humans who received an allogenic faecal transplant from lean donors [17]. This finding was associated with improved insulin sensitivity. Altogether, nutrition, in concert with the gut microbiome and the host, influences intestinal motility and the enteroendocrine system.

Endogenous enzymes Alongside the recognition of microbial metabolites by metabolite-sensing receptors, endogenously expressed enzymes further process microbial metabolites to influence host responses to microbial metabolites. Trimethylamineoxide (TMAO) is the most-studied dietderived microbial metabolite and has been shown to have a strong association with cardiovascular disease development [90]. Dietary choline and carnitine can be converted into trimethylamine (TMA) by TMA-lyase-expressing bacteria in the gut. TMA is converted into TMAO in the liver by flavinecontaining monooxygenase 3 (FMO3). TMAO has been linked to cardiovascular disease development in humans and mice via mechanisms that include blood platelet hyperresponsiveness [91, 92], decreased reverse cholesterol transport [90] and macrophage cholesterol accumulation [93]. Although TMAO has been implicated in the regulation of inflammatory pathways $[94,95]$ and endoplasmic reticulum stress [96] (both of relevance for type 2 diabetes development), evidence for a role of TMAO in type 2 diabetes is scarce [97]. Nonetheless, considering the fact that most people with type 2 diabetes will develop cardiovascular disease, we assume that TMAO might also play a role in type 2 diabetes.

The histidine derivative imidazole propionate (ImP), which is produced by microbes, is of specific interest in relation to type 2 diabetes as it was found to be positively correlated with insulin resistance in humans [98]. Although a receptor has not yet been identified, ImP was shown to directly inhibit hepatic insulin receptor substrate signalling in mice, with p38 mitogen-activated protein kinase (MAPK)-mediated hyperactivation of the mechanistic target of rapamycin complex 1 (mTORC1) being identified as a central regulatory mechanism [98]. In a recent study in humans on the extreme end of cardiometabolic disease (obese and hyperglycaemic), the microbial metabolite 4-cresol negatively correlated with type 2 diabetes [99]. Although 4-cresol can be derived directly from food, it is also a product of tyrosine and phenylalanine 


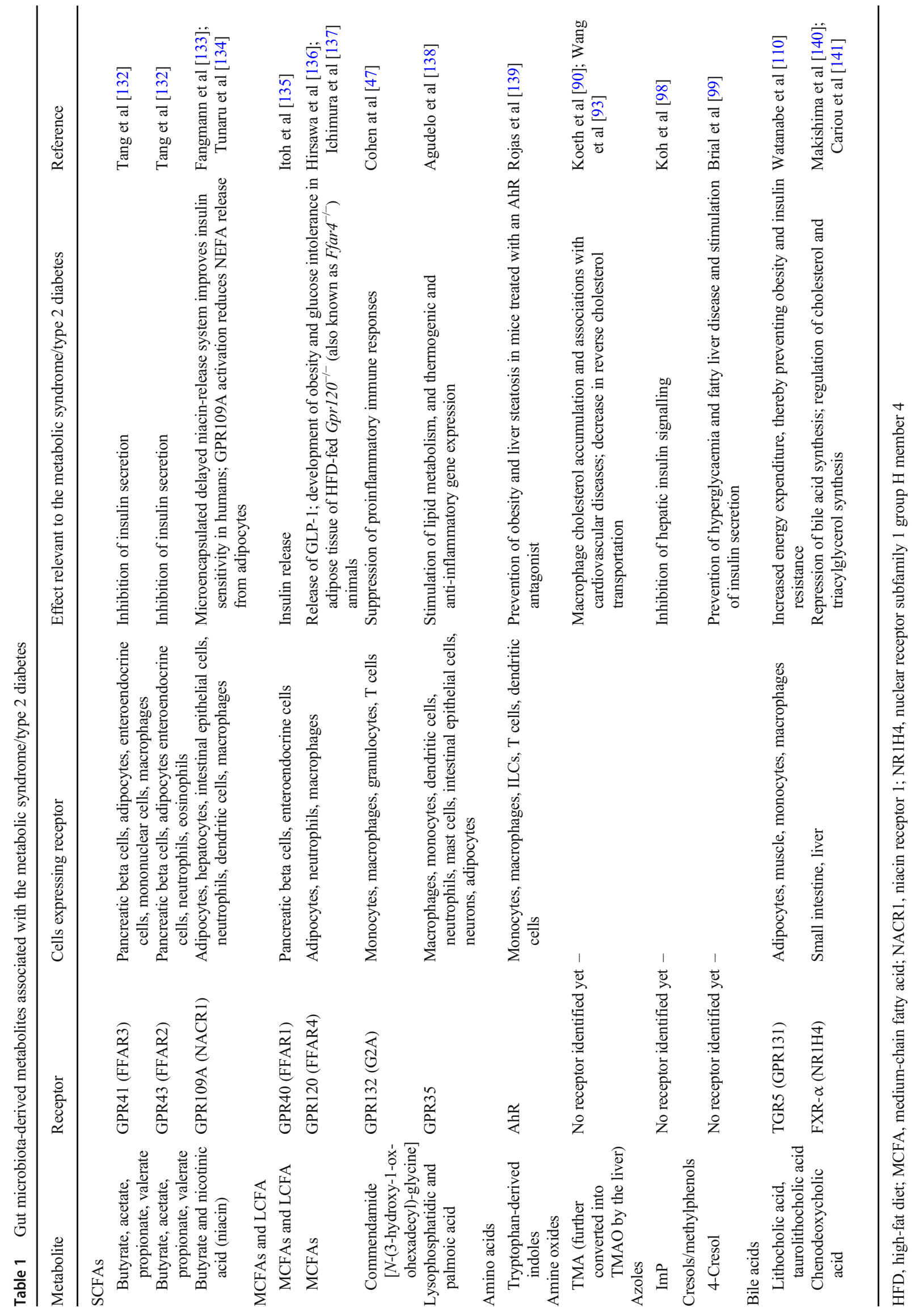


fermentation in the colon. Subcutaneous administration of 4cresol prevented development of hyperglycaemia and fatty liver in mice fed a high-fat diet [99]. In line with observations that 4-cresol increases insulin secretion, this metabolite downregulated the expression of dual-specificity tyrosine-regulated kinase-1a (DYRK1A) [99], which has been shown to facilitate pancreatic beta cell proliferation [100]. In addition, Lactobacillus plantarum, Enterococcus faecalis and Bacteroides thetaiotaomicron produce LCFAs, including conjugated linoleic acids (CLAs) [101]. LCFAs serve as precursors for lipid mediators such as arachidonic acid, which has been implicated in metabolic improvement in humans [102]. CLA was shown to alter fatty acid metabolism and reduce body fat content in humans with obesity [103].

Endogenous metabolites The host also secretes endogenously generated metabolites into the intestine, where the microbiome further modifies these products. Bile acids are an important class of endogenous molecules required for the digestion of dietary fats and oils, absorption of fat-soluble vitamins, and elimination of cholesterol and bilirubin that undergo microbial conversion in the large intestine. Moreover, bile acids have long been implicated in the regulation of human metabolism and development of metabolic diseases including type 2 diabetes [104]. Bile acids are produced from cholesterol in the liver and secreted as primary bile acids in the small intestine where they aid in absorption of dietary lipids and vitamins. Although the vast majority of bile acids are reabsorbed in the distal small intestine, a small amount ends up in the colon where, depending on microbiome composition, they are converted into secondary or tertiary bile acids $[105,106]$. These hydrophobic molecules easily diffuse into the circulation to bind to a broad range of receptors. The signalling properties of bile acids of relevance for type 2 diabetes are, in large, mediated via the $\mathrm{G}$ protein-linked receptor TGR5 and the farnesoid X receptor (FXR), both of which have high affinity for hydrophobic bile acids. In mice, activation of TGR5 by bile acids has been shown to induce GLP-1 secretion [107], to be immunosuppressive [108] and to increase energy expenditure [109, 110]. Regulation of metabolism by FXR is marked by contradicting findings since bile acids can serve as either FXR agonists or antagonists. In addition, differential regulation of FXR signalling in tissues with high expression of this nuclear receptor (most notably intestine and liver) is likely to account for the discrepancies in the field. Both activation [111, 112] and inhibition [113-115] of FXR has been shown to have beneficial effects on obesity and insulin resistance. Of importance, most of the insights into the role of FXR in the regulation of metabolism have been derived from studies in mice, which have a vastly different bile acid composition to humans [104].

Taken together, food-, host- and microbe-derived metabolites influence multiple processes required for intestinal immunity, intestinal motility and maintenance of the enteroendocrine system, all of which may be affected in individuals with the metabolic syndrome.

\section{Possible interventions}

Diet Since dietary components are used by gut microbes to produce metabolites, dietary interventions are an interesting non-pharmacological approach to altering (potentially harmful) microbial metabolites, with the aim of benefitting individuals with the metabolic syndrome or type 2 diabetes. Dietary interventions are, however, often challenged by limited adherence. In addition, the so-called substitution effect, where alterations in macronutrient composition are usually inevitable in order to establish isoenergetic diets [116], can be a critical confounding factor. This 'swapping' of macronutrients can have vast consequences for the microbiome or can directly alter human metabolism to blur effects mediated by the microbiome. It is too early to tell whether dietary strategies aimed at reducing precursors (e.g. choline, histidine) of potentially harmful metabolites (e.g. TMAO, ImP) will indeed lead to reduced development of type 2 diabetes in the long term. Targeting bacterial enzymes, such as bile salt hydrolase (responsible for conversion of primary to secondary bile acids) or TMA lyase (responsible for conversion of choline to TMA), might hold great potential.

Importantly, dietary interventions are generally characterised by a highly personal response (i.e. success of diet) $[10,117,118]$. Interestingly, it has been shown that gut microbiome data from individuals with the metabolic syndrome with differential postprandial glucose responses can be used to generate a machine learning algorithm that can predict the individual response to and success of a particular dietary regimen in a separate cohort, based on their baseline microbiome composition [119]. Although metabolites were not addressed in this study, a similar approach can be used to develop dietary strategies best suited to alter metabolite production based on baseline microbiome genetic potential. In a study by Zhao and co-workers, participants with type 2 diabetes were administered large amounts of dietary fibres [120]. Using a metagenomics approach, gut microbiome responses was measured and linked to glucometabolic response. Participants that benefited from a high-fibre diet (e.g. who had improved $\mathrm{HbA}_{1 \mathrm{c}}$ and reduced body weight) and had increased gut SCFA concentrations were characterised as having increased abundance of specific SCFA-producing bacteria and coincided with increased faecal SCFA levels after the intervention. These study findings strongly suggest that dietary intervention studies aimed at altering microbial metabolite production can be successful but only when using a personal approach based on baseline microbial potential. In addition, they might explain, in part, 
the many discrepancies observed in the success of dietary interventions.

SCFAs Direct supplementation with SCFAs has thus far not yielded overwhelming (perhaps anticipated based on mouse data) evidence for improvements in glucometabolic variables in humans with the metabolic syndrome or type 2 diabetes. One study in obese individuals showed that colonic infusion of propionate stimulated release of PYY and GLP-1 and reduced energy intake, potentially via regulation of satiety [121]. In addition, insulin sensitivity in participants receiving propionate stabilised, whereas deterioration was observed in those in the control group. Acetate infusion into the distal colon was shown to increase fatty acid oxidation and PYY release while also increasing postprandial glucose and insulin levels [122]. However, supplementation with sodium butyrate for 1 month did not alter hepatic or peripheral insulin sensitivity in men with the metabolic syndrome [123]. Of interest, butyrate did improve insulin sensitivity in lean participants. This effect was attributed to putative differences in intestinal SCFA handling in obese vs lean humans, although this hypothesis remains to be tested in well-designed (stable isotope) studies in participants with type 2 diabetes. As pointed out earlier, care should be taken when interpreting studies involving SCFAs in humans since SCFA 'faith' and turnover is difficult to measure. An important basis for much needed clinical trials addressing SCFA fluxes in the metabolic syndrome and type 2 diabetes was highlighted by Boets et al [124]. Systemic availability and conversion of SCFA was quantified in lean participants receiving colon-delivery capsules containing ${ }^{13} \mathrm{C}$-labelled SCFA. In the circulation, $36 \%, 9 \%$ and $2 \%$ of administered acetate, propionate and butyrate, respectively, was detected. In addition, a major proportion of acetate (24\%) was converted into butyrate or incorporated into cholesterol (1\%) and fatty acids (15\%). An estimated $6 \%$ of propionate was incorporated into glucose. Faecal SCFA concentrations varied greatly between individuals, as observed in several other studies in humans [125, 126], potentially due to differences in microbial genetic capacity, which was not addressed in this study.

Bile acids Given the many effects of bile acids on the characteristics of the metabolic syndrome and type 2 diabetes, altering human metabolism via bile acids or bile acid receptormediated signalling is an appealing, yet complicated, approach. As indicated, there are vast differences between mouse and human bile acid composition. Hence, data from mouse studies are difficult to extrapolate to humans. Strategies for altering bile acid composition/signalling via the gut microbiome in the context of the metabolic syndrome or type 2 diabetes are, to the best of our knowledge, scarce. Ursodeoxycholic acid (also known as ursodiol [UDCA]) was shown to improve metabolism in mice fed a high-fat diet
[127]. Because UDCA is approved by the US Food and Drug Administration as a safe treatment option for primary biliary cholangitis, it might be a safe treatment option for the metabolic syndrome. A clinical trial using oral UDCA in humans is currently ongoing (ClinicalTrials.gov registration no. NCT02033876).

Furthermore, in an interim analysis of an ongoing multicentre, randomised, double-blinded, placebo-controlled trial, the FXR agonist obeticholic acid $(25 \mathrm{mg})$ improved fibrosis and non-alcoholic steatohepatitis (NASH) disease activity in $23 \%$ of participants with F1-F3 fibrosis assessed by histological scoring. Fifty-one per cent of the participants with NASH receiving obeticholic acid developed pruritus, which may hinder the usage of obeticholic acid in the majority of people with NASH [128].

FMT FMT involves the transfer of the faecal microbiota from a healthy, screened donor to a recipient. FMT is currently only approved as a treatment strategy for recurrent Clostridium difficile infections and not for the treatment of the metabolic syndrome or type 2 diabetes. Despite several challenges with current FMT protocols, such as standardisation and preparation of the transplant and the route of administration, FMT can be a useful research tool to study the effect of gut microbiome and microbial metabolites on human metabolism [129]. FMT leads to major (albeit temporary in a significant number of recipients) changes in microbiome composition. Although metabolite data are not generally available in FMT studies in recipients with type 2 diabetes, it is plausible that metabolite production is also altered. One study showed that improvements in insulin sensitivity coincided with changes in beneficial microbes and microbial metabolites in insulin-resistant recipients [17]. FMT can, therefore, serve an important role in identification (mining) of novel strains and metabolites to be further studied in relevant model systems and clinical trials. This field is in the early stages and microbial metabolites, with the exception of SCFA, have not yet entered clinical trials.

FMT has been used as a useful research tool to identify novel bacterial strains. For example, in one study the butyrogenic strain Anaerobutyricum soehngenii was identified to positively correlate with improved insulin sensitivity after FMT [18]. In a recently published phase I/II trial in humans with the metabolic syndrome, supplementation with A. soehngenii was shown to be safe and to improve insulin sensitivity after 4 weeks of daily treatment [130]. Although no effect on faecal SCFA levels was observed in the given setting, trials like these will open up more treatment opportunities using microbial metabolites. It is possible that in the future it will be sufficient to supplement humans with the metabolic syndrome or type 2 diabetes with defined microbes or metabolites instead of transplanting the entire microbiome. In a randomised, placebo-controlled proof-of-concept exploratory study, Akkermansia muciniphilia supplementation for 
3 months improved insulin sensitivity, reduced plasma cholesterol and decreased body weight [131].

\section{Future perspectives}

Increasing evidence suggests that not only microbes and their structural components but also their metabolites influence host responses and may contribute to the development of the metabolic syndrome and type 2 diabetes. A better understanding of the relationship between the microbiome (and its metabolites) with the host will increase our knowledge on the development of the metabolic syndrome and type 2 diabetes. This is also likely to give insight into how the development of the metabolic syndrome and type 2 diabetes can be prevented and will pave the way to novel approaches for the treatment of type 2 diabetes. Before this fascinating research enters daily practice, we anticipate the following frontiers that need to be further studied.

1. Increasing numbers of studies show an association of an altered gut microbiome and its metabolome with the metabolic syndrome/type 2 diabetes. Currently the field is strongly moving towards causal/mechanistic studies, in which individual microbes or metabolites will be identified that may contribute to the metabolic syndrome/type 2 diabetes. Ideally, these studies will integrate host genetics to characterise the relationship between the microbiome and the host in the contexts of the metabolic syndrome/ type 2 diabetes.

2. The characterisation of metabolite-sensing receptors and their microbial ligands will provide new options for pharmacological interventions for the metabolic syndrome and type 2 diabetes. Before metabolite-sensing receptors such as GPCRs can be targeted by small molecules, the characterisation of ligand specificity of each unique receptor is required, as most ligands/metabolites are promiscuous and bind to different receptors. Collaborations between academic investigators and the pharmaceutical industry may solve these issues.

3. Because dietary interventions are characterised by personal responses, microbiome data together with glucose response data will predict, via machine learning algorithms, individual response to interventions in personalised medicine approaches in the near future. This will require interdisciplinary teams including microbiologists/molecular biologists, bioinformaticians, endocrinologists, gastroenterologists and nutritional counselling. It is likely that only large and dedicated institutions can provide such an environment, which may hinder the introduction of personalised nutrition in daily practice.
With this knowledge, in the future it will be possible to move the fascinating microbiome research into the clinic, beyond only studying associations between the microbiome and the metabolic syndrome/type 2 diabetes. The altered microbiome in the metabolic syndrome/type 2 diabetes might be corrected in future to treat individuals with the metabolic syndrome/type 2 diabetes.

Funding Information Open access funding provided by University of Basel. The SNSF grant 310030_175548 to JHN supported the writing of this manuscript. HH is supported by a Senior Fellowship (2019.82.004) of the Dutch Diabetes Research Foundation.

Authors' relationships and activities The authors declare that there are no relationships or activities that might bias, or be perceived to bias, their work.

Contribution statement Both authors substantially contributed to the conception, design and interpretation of the published literature cited in this review. Both authors jointly drafted the article, critically revised the review and approved the final version for publication.

Open Access This article is licensed under a Creative Commons Attribution 4.0 International License, which permits use, sharing, adaptation, distribution and reproduction in any medium or format, as long as you give appropriate credit to the original author(s) and the source, provide a link to the Creative Commons licence, and indicate if changes were made. The images or other third party material in this article are included in the article's Creative Commons licence, unless indicated otherwise in a credit line to the material. If material is not included in the article's Creative Commons licence and your intended use is not permitted by statutory regulation or exceeds the permitted use, you will need to obtain permission directly from the copyright holder. To view a copy of this licence, visit http://creativecommons.org/licenses/by/4.0/.

\section{References}

1. Ogurtsova K, da Rocha Fernandes JD, Huang Y et al (2017) IDF DIABETES Atlas: global estimates for the prevalence of diabetes for 2015 and 2040. Diabetes Res Clin Pract 128:40-50. https:// doi.org/10.1016/j.diabres.2017.03.024

2. Saeedi P, Petersohn I, Salpea P et al (2019) Global and regional diabetes prevalence estimates for 2019 and projections for 2030 and 2045: results from the International Diabetes Federation diabetes atlas, $9^{\text {th }}$ edition. Diabetes Res Clin Pract 157:107843. https://doi.org/10.1016/j.diabres.2019.107843

3. Snijder MB, Agyemang C, Peters RJ, Stronks K, Ujcic-Voortman JK, van Valkengoed IG (2017) Case finding and medical treatment of type 2 diabetes among different ethnic minority groups: the HELIUS study. J Diabetes Res 2017:9896849. https://doi.org/ 10.1155/2017/9896849

4. Cheng YJ, Kanaya AM, Araneta MRG et al (2019) Prevalence of diabetes by race and ethnicity in the United States, 2011-2016. JAMA 322(24):2389-2398. https://doi.org/10.1001/jama.2019. 19365

5. Tillin T, Hughes AD, Godsland IF et al (2013) Insulin resistance and truncal obesity as important determinants of the greater incidence of diabetes in Indian Asians and African Caribbeans compared with Europeans: the Southall And Brent REvisited 
(SABRE) cohort. Diabetes Care 36(2):383-393. https://doi.org/ $10.2337 / \mathrm{dc} 12-0544$

6. Mahajan A, Wessel J, Willems SM et al (2018) Refining the accuracy of validated target identification through coding variant fine-mapping in type 2 diabetes. Nat Genet 50(4):559-571. https://doi.org/10.1038/s41588-018-0084-1

7. McCarthy MI (2010) Genomics, type 2 diabetes, and obesity. $\mathrm{N}$ Engl J Med 363(24):2339-2350. https://doi.org/10.1056/ NEJMra0906948

8. Morris AP, Voight BF, Teslovich TM et al (2012) Large-scale association analysis provides insights into the genetic architecture and pathophysiology of type 2 diabetes. Nat Genet 44(9):981990. https://doi.org/10.1038/ng.2383

9. Saklayen MG (2018) The global epidemic of the metabolic syndrome. Curr Hypertens Rep 20(2):12. https://doi.org/10. 1007/s11906-018-0812-z

10. Cotillard A, Kennedy SP, Kong LC et al (2013) Dietary intervention impact on gut microbial gene richness. Nature 500(7464): 585-588. https://doi.org/10.1038/nature12480

11. Le Chatelier E, Nielsen T, Qin J et al (2013) Richness of human gut microbiome correlates with metabolic markers. Nature 500(7464):541-546. https://doi.org/10.1038/nature12506

12. Li SS, Zhu A, Benes V et al (2016) Durable coexistence of donor and recipient strains after fecal microbiota transplantation. Science 352(6285):586-589. https://doi.org/10.1126/science.aad8852

13. Del Chierico F, Abbatini F, Russo A et al (2018) Gut microbiota markers in obese adolescent and adult patients: age-dependent differential patterns. Front Microbiol 9:1210. https://doi.org/10. 3389/fmicb.2018.01210

14. Ussar S, Griffin NW, Bezy O et al (2015) Interactions between gut microbiota, host genetics and diet modulate the predisposition to obesity and metabolic syndrome. Cell Metab 22(3):516-530. https://doi.org/10.1016/j.cmet.2015.07.007

15. Turnbaugh PJ, Ley RE, Mahowald MA, Magrini V, Mardis ER, Gordon JI (2006) An obesity-associated gut microbiome with increased capacity for energy harvest. Nature 444(7122):10271031. https://doi.org/10.1038/nature05414

16. Ridaura VK, Faith JJ, Rey FE et al (2013) Gut microbiota from twins discordant for obesity modulate metabolism in mice. Science 341(6150):1241214. https://doi.org/10.1126/science. 1241214

17. Kootte RS, Levin E, Salojarvi J et al (2017) Improvement of insulin sensitivity after lean donor feces in metabolic syndrome is driven by baseline intestinal microbiota composition. Cell Metab 26(4):611-619 e616. https://doi.org/10.1016/j.cmet.2017. 09.008

18. Vrieze A, Van Nood E, Holleman F et al (2012) Transfer of intestinal microbiota from lean donors increases insulin sensitivity in individuals with metabolic syndrome. Gastroenterology 143(4): 913-916. https://doi.org/10.1053/j.gastro.2012.06.031

19. de Groot P, Scheithauer T, Bakker GJ et al (2020) Donor metabolic characteristics drive effects of faecal microbiota transplantation on recipient insulin sensitivity, energy expenditure and intestinal transit time. Gut 69(3):502-512. https://doi.org/10.1136/ gutjnl-2019-318320

20. Gurung M, Li Z, You H et al (2020) Role of gut microbiota in type 2 diabetes pathophysiology. EBioMedicine 51:102590. https:// doi.org/10.1016/j.ebiom.2019.11.051

21. Wu G, Zhang C, Wu H et al (2017) Genomic microdiversity of Bifidobacterium pseudocatenulatum underlying differential strain-level responses to dietary carbohydrate intervention. $\mathrm{mBio}$ 8(1):e02348-16. https://doi.org/10.1128/mBio.02348-16

22. Ley RE, Turnbaugh PJ, Klein S, Gordon JI (2006) Microbial ecology: human gut microbes associated with obesity. Nature 444(7122):1022-1023. https://doi.org/10.1038/4441022a
23. Murphy EF, Cotter PD, Healy S et al (2010) Composition and energy harvesting capacity of the gut microbiota: relationship to diet, obesity and time in mouse models. Gut 59(12):1635-1642. https://doi.org/10.1136/gut.2010.215665

24. Duncan SH, Lobley GE, Holtrop G et al (2008) Human colonic microbiota associated with diet, obesity and weight loss. Int $\mathrm{J}$ Obes 32(11):1720-1724. https://doi.org/10.1038/ijo.2008.155

25. Zhang H, DiBaise JK, Zuccolo A et al (2009) Human gut microbiota in obesity and after gastric bypass. Proc Natl Acad Sci U S A 106(7):2365-2370. https://doi.org/10.1073/pnas.0812600106

26. Schwiertz A, Taras D, Schafer K et al (2010) Microbiota and SCFA in lean and overweight healthy subjects. Obesity $18(1)$ : 190-195. https://doi.org/10.1038/oby.2009.167

27. Karlsson FH, Tremaroli V, Nookaew I et al (2013) Gut metagenome in European women with normal, impaired and diabetic glucose control. Nature 498(7452):99-103. https://doi. org/10.1038/nature12198

28. Larsen N, Vogensen FK, van den Berg FW et al (2010) Gut microbiota in human adults with type 2 diabetes differs from non-diabetic adults. PLoS One 5(2):e9085. https://doi.org/10. 1371/journal.pone.0009085

29. Qin J, Li Y, Cai Z et al (2012) A metagenome-wide association study of gut microbiota in type 2 diabetes. Nature 490(7418):5560. https://doi.org/10.1038/nature11450

30. Gomes JMG, Costa JA, Alfenas RCG (2017) Metabolic endotoxemia and diabetes mellitus: a systematic review. Metabolism 68:133-144. https://doi.org/10.1016/j.metabol.2016. 12.009

31. Cani PD, Amar J, Iglesias MA et al (2007) Metabolic endotoxemia initiates obesity and insulin resistance. Diabetes 56(7):1761-1772. https://doi.org/10.2337/db06-1491

32. Lassenius MI, Pietilainen KH, Kaartinen K et al (2011) Bacterial endotoxin activity in human serum is associated with dyslipidemia, insulin resistance, obesity, and chronic inflammation. Diabetes Care 34(8):1809-1815. https://doi.org/10.2337/dc102197

33. Serpa J, Caiado F, Carvalho T et al (2010) Butyrate-rich colonic microenvironment is a relevant selection factor for metabolically adapted tumor cells. J Biol Chem 285(50):39211-39223. https:// doi.org/10.1074/jbc.M110.156026

34. Flint HJ, Duncan SH, Scott KP, Louis P (2015) Links between diet, gut microbiota composition and gut metabolism. Proc Nutr Soc 74(1):13-22. https://doi.org/10.1017/S0029665114001463

35. de la Cuesta-Zuluaga J, Mueller NT, Alvarez-Quintero R et al (2018) Higher fecal short-chain fatty acid levels are associated with gut microbiome dysbiosis, obesity, hypertension and cardiometabolic disease risk factors. Nutrients 11(1). https://doi.org/10. 3390/nu11010051

36. Rahat-Rozenbloom S, Fernandes J, Gloor GB, Wolever TM (2014) Evidence for greater production of colonic short-chain fatty acids in overweight than lean humans. Int J Obes 38(12): 1525-1531. https://doi.org/10.1038/ijo.2014.46

37. Jumpertz R, Le DS, Turnbaugh PJ et al (2011) Energy-balance studies reveal associations between gut microbes, caloric load, and nutrient absorption in humans. Am J Clin Nutr 94(1):58-65. https://doi.org/10.3945/ajcn.110.010132

38. Dominguez-Bello MG, De Jesus-Laboy KM, Shen N et al (2016) Partial restoration of the microbiota of cesarean-born infants via vaginal microbial transfer. Nat Med 22(3):250-253. https://doi. org/10.1038/nm.4039

39. Backhed F, Roswall J, Peng Y et al (2015) Dynamics and stabilization of the human gut microbiome during the first year of life. Cell Host Microbe 17(5):690-703. https://doi.org/10.1016/j. chom.2015.04.004 
40. Steinert A, Radulovic K, Niess J (2016) Gastro-intestinal tract: the leading role of mucosal immunity. Swiss Med Wkly 146:w14293. https://doi.org/10.4414/smw.2016.14293

41. Degnan PH, Taga ME, Goodman AL (2014) Vitamin $B_{12}$ as a modulator of gut microbial ecology. Cell Metab 20(5):769-778. https://doi.org/10.1016/j.cmet.2014.10.002

42. Miki T, Goto R, Fujimoto M, Okada N, Hardt WD (2017) The bactericidal lectin RegIII $\beta$ prolongs gut colonization and enteropathy in the streptomycin mouse model for Salmonella diarrhea. Cell Host Microbe 21(2):195-207. https://doi.org/10.1016/j. chom.2016.12.008

43. Devlin AS, Fischbach MA (2015) A biosynthetic pathway for a prominent class of microbiota-derived bile acids. Nat Chem Biol 11(9):685-690. https://doi.org/10.1038/nchembio.1864

44. Niess JH, Leithauser F, Adler G, Reimann J (2008) Commensal gut flora drives the expansion of proinflammatory CD4 T cells in the colonic lamina propria under normal and inflammatory conditions. J Immunol 180(1):559-568. https://doi.org/10.4049/ jimmunol.180.1.559

45. Ivanov II, Atarashi K, Manel N et al (2009) Induction of intestinal Th17 cells by segmented filamentous bacteria. Cell 139(3):485498. https://doi.org/10.1016/j.cell.2009.09.033

46. Yang $\mathrm{H}, \mathrm{Yu} \mathrm{HB}$, Bhinder $\mathrm{G}$ et al (2019) TLR9 limits enteric antimicrobial responses and promotes microbiota-based colonisation resistance during Citrobacter rodentium infection. Cell Microbiol 21(7):e13026. https://doi.org/10.1111/cmi.13026

47. Cohen LJ, Kang HS, Chu J et al (2015) Functional metagenomic discovery of bacterial effectors in the human microbiome and isolation of commendamide, a GPCR G2A/132 agonist. Proc Natl Acad Sci U S A 112(35):E4825-E4834. https://doi.org/10. 1073/pnas. 1508737112

48. Caruso R, Lo BC, Nunez G (2020) Host-microbiota interactions in inflammatory bowel disease. Nat Rev Immunol 20(7):411-426. https://doi.org/10.1038/s41577-019-0268-7

49. Kinugasa T, Sakaguchi T, Gu X, Reinecker HC (2000) Claudins regulate the intestinal barrier in response to immune mediators. Gastroenterology 118(6):1001-1011. https://doi.org/10.1016/ s0016-5085(00)70351-9

50. Salzman NH, Hung K, Haribhai D et al (2010) Enteric defensins are essential regulators of intestinal microbial ecology. Nat Immunol 11(1):76-83. https://doi.org/10.1038/ni.1825

51. Smythies LE, Sellers M, Clements RH et al (2005) Human intestinal macrophages display profound inflammatory anergy despite avid phagocytic and bacteriocidal activity. J Clin Invest 115(1): 66-75. https://doi.org/10.1172/JCI19229

52. Chen K, Magri G, Grasset EK, Cerutti A (2020) Rethinking mucosal antibody responses: $\operatorname{IgM}$, IgG and $\operatorname{IgD}$ join $\operatorname{IgA}$. Nat Rev Immunol 20(7):427-441. https://doi.org/10.1038/s41577-0190261-1

53. Moor K, Diard M, Sellin ME et al (2017) High-avidity IgA protects the intestine by enchaining growing bacteria. Nature 544(7651):498-502. https://doi.org/10.1038/nature22058

54. Donaldson GP, Ladinsky MS, Yu KB et al (2018) Gut microbiota utilize immunoglobulin A for mucosal colonization. Science 360(6390):795-800. https://doi.org/10.1126/science.aaq0926

55. Balmer ML, Slack E, de Gottardi A et al (2014) The liver may act as a firewall mediating mutualism between the host and its gut commensal microbiota. Sci Transl Med 6(237):237ra266. https:// doi.org/10.1126/scitranslmed.3008618

56. Massier L, Chakaroun R, Tabei S et al (2020) Adipose tissue derived bacteria are associated with inflammation in obesity and type 2 diabetes. Gut. https://doi.org/10.1136/gutjnl-2019-320118
57. Sookoian S, Salatino A, Castano GO et al (2020) Intrahepatic bacterial metataxonomic signature in non-alcoholic fatty liver disease. Gut 69:1483-1491. https://doi.org/10.1136/gutjnl-2019318811

58. Tilg H, Zmora N, Adolph TE, Elinav E (2020) The intestinal microbiota fuelling metabolic inflammation. Nat Rev Immunol 20(1):40-54. https://doi.org/10.1038/s41577-019-0198-4

59. Wikoff WR, Anfora AT, Liu J et al (2009) Metabolomics analysis reveals large effects of gut microflora on mammalian blood metabolites. Proc Natl Acad Sci U S A 106(10):3698-3703. https://doi. org/10.1073/pnas.0812874106

60. Guasch-Ferre M, Hruby A, Toledo E et al (2016) Metabolomics in prediabetes and diabetes: a systematic review and meta-analysis. Diabetes Care 39(5):833-846. https://doi.org/10.2337/dc15-2251

61. Rabaglia ME, Gray-Keller MP, Frey BL, Shortreed MR, Smith LM, Attie AD (2005) $\alpha$-Ketoisocaproate-induced hypersecretion of insulin by islets from diabetes-susceptible mice. Am J Physiol Endocrinol Metab 289(2):E218-E224. https://doi.org/10.1152/ ajpendo.00573.2004

62. Yang J, Chi Y, Burkhardt BR, Guan Y, Wolf BA (2010) Leucine metabolism in regulation of insulin secretion from pancreatic beta cells. Nutr Rev 68(5):270-279. https://doi.org/10.1111/j.17534887.2010.00282.x

63. Myhrvold C, Kotula JW, Hicks WM, Conway NJ, Silver PA (2015) A distributed cell division counter reveals growth dynamics in the gut microbiota. Nat Commun 6:10039. https://doi.org/ 10.1038/ncomms10039

64. Li H, Limenitakis JP, Fuhrer T et al (2015) The outer mucus layer hosts a distinct intestinal microbial niche. Nat Commun 6:8292. https://doi.org/10.1038/ncomms9292

65. El Aidy S, Merrifield CA, Derrien M et al (2013) The gut microbiota elicits a profound metabolic reorientation in the mouse jejunal mucosa during conventionalisation. Gut 62(9):1306-1314. https://doi.org/10.1136/gutjnl-2011-301955

66. Nicholls AW, Mortishire-Smith RJ, Nicholson JK (2003) NMR spectroscopic-based metabonomic studies of urinary metabolite variation in acclimatizing germ-free rats. Chem Res Toxicol 16(11):1395-1404. https://doi.org/10.1021/tx0340293

67. Williams RE, Eyton-Jones HW, Farnworth MJ, Gallagher R, Provan WM (2002) Effect of intestinal microflora on the urinary metabolic profile of rats: a ${ }^{1} \mathrm{H}$-nuclear magnetic resonance spectroscopy study. Xenobiotica 32(9):783-794. https://doi.org/10. 1080/00498250210143047

68. Uchimura Y, Fuhrer T, Li H et al (2018) Antibodies set boundaries limiting microbial metabolite penetration and the resultant mammalian host response. Immunity 49(3):545-559. https://doi. org/10.1016/j.immuni.2018.08.004

69. Yang C, Mogno I, Contijoch EJ et al (2020) Fecal IgA levels are determined by strain-level differences in bacteroides ovatus and are modifiable by gut microbiota manipulation. Cell Host Microbe 27(3):467-475. https://doi.org/10.1016/j.chom.2020.01.016

70. Hapfelmeier S, Lawson MA, Slack E et al (2010) Reversible microbial colonization of germ-free mice reveals the dynamics of IgA immune responses. Science 328(5986):1705-1709. https://doi.org/10.1126/science.1188454

71. Melhem H, Kaya B, Ayata CK, Hruz P, Niess JH (2019) Metabolite-sensing G protein-coupled receptors connect the dietmicrobiota-metabolites axis to inflammatory bowel disease. Cells 8(5):450. https://doi.org/10.3390/cells8050450

72. Tan JK, McKenzie C, Marino E, Macia L, Mackay CR (2017) Metabolite-sensing $\mathrm{G}$ protein-coupled receptors-facilitators of diet-related immune regulation. Annu Rev Immunol 35:371402. https://doi.org/10.1146/annurev-immunol-051116-052235 
73. Frost G, Sleeth ML, Sahuri-Arisoylu M et al (2014) The shortchain fatty acid acetate reduces appetite via a central homeostatic mechanism. Nat Commun 5:3611. https://doi.org/10.1038/ ncomms 4611

74. Kimura I, Ozawa K, Inoue D et al (2013) The gut microbiota suppresses insulin-mediated fat accumulation via the short-chain fatty acid receptor GPR43. Nat Commun 4:1829. https://doi.org/ $10.1038 /$ ncomms 2852

75. Tolhurst G, Heffron H, Lam YS et al (2012) Short-chain fatty acids stimulate glucagon-like peptide- 1 secretion via the Gprotein-coupled receptor FFAR2. Diabetes 61(2):364-371. https://doi.org/10.2337/db11-1019

76. Larraufie P, Martin-Gallausiaux C, Lapaque N et al (2018) SCFAs strongly stimulate PYY production in human enteroendocrine cells. Sci Rep 8(1):74. https://doi.org/10.1038/s41598-01718259-0

77. Davie JR (2003) Inhibition of histone deacetylase activity by butyrate. J Nutr 133(7 Suppl):2485S-2493S. https://doi.org/10.1093/ $\mathrm{jn} / 133.7 .2485 \mathrm{~S}$

78. den Besten G, Lange K, Havinga R et al (2013) Gut-derived shortchain fatty acids are vividly assimilated into host carbohydrates and lipids. Am J Physiol Gastrointest Liver Physiol 305(12): G900-G910. https://doi.org/10.1152/ajpgi.00265.2013

79. Wolever TM, Brighenti F, Royall D, Jenkins AL, Jenkins DJ (1989) Effect of rectal infusion of short chain fatty acids in human subjects. Am J Gastroenterol 84(9):1027-1033

80. Stockinger B, Di Meglio P, Gialitakis M, Duarte JH (2014) The aryl hydrocarbon receptor: multitasking in the immune system. Annu Rev Immunol 32:403-432. https://doi.org/10.1146/ annurev-immunol-032713-120245

81. Opitz CA, Litzenburger UM, Sahm F et al (2011) An endogenous tumour-promoting ligand of the human aryl hydrocarbon receptor. Nature 478(7368):197-203. https://doi.org/10.1038/nature10491

82. Lavelle A, Sokol H (2020) Gut microbiota-derived metabolites as key actors in inflammatory bowel disease. Nat Rev Gastroenterol Hepatol 17(4):223-237. https://doi.org/10.1038/s41575-019$0258-\mathrm{Z}$

83. Obata Y, Castano A, Boeing S et al (2020) Neuronal programming by microbiota regulates intestinal physiology. Nature 578(7794):284-289. https://doi.org/10.1038/s41586-020-1975-8

84. Qiu J, Heller JJ, Guo X et al (2012) The aryl hydrocarbon receptor regulates gut immunity through modulation of innate lymphoid cells. Immunity 36(1):92-104. https://doi.org/10.1016/j.immuni. 2011.11.011

85. Talbot J, Hahn P, Kroehling L, Nguyen H, Li D, Littman DR (2020) Feeding-dependent VIP neuron-ILC3 circuit regulates the intestinal barrier. Nature 579(7800):575-580. https://doi.org/10. 1038/s41586-020-2039-9

86. Strandwitz P (2018) Neurotransmitter modulation by the gut microbiota. Brain Res 1693:128-133. https://doi.org/10.1016/j. brainres.2018.03.015

87. Barrett E, Ross RP, O'Toole PW, Fitzgerald GF, Stanton C (2012) $\gamma$-Aminobutyric acid production by culturable bacteria from the human intestine. J Appl Microbiol 113(2):411-417. https://doi. org/10.1111/j.1365-2672.2012.05344.x

88. Soltani N, Qiu H, Aleksic M et al (2011) GABA exerts protective and regenerative effects on islet beta cells and reverses diabetes. Proc Natl Acad Sci U S A 108(28):11692-11697. https://doi.org/ 10.1073/pnas.1102715108

89. Tian J, Dang H, Chen Z et al (2013) $\gamma$-Aminobutyric acid regulates both the survival and replication of human $\beta$-cells. Diabetes 62(11):3760-3765. https://doi.org/10.2337/db13-0931
90. Koeth RA, Wang Z, Levison BS et al (2013) Intestinal microbiota metabolism of L-carnitine, a nutrient in red meat, promotes atherosclerosis. Nat Med 19(5):576-585. https://doi.org/10.1038/nm. 3145

91. Zhu W, Gregory JC, Org E et al (2016) Gut microbial metabolite TMAO enhances platelet hyperreactivity and thrombosis risk. Cell 165(1):111-124. https://doi.org/10.1016/j.cell.2016.02.011

92. Zhu W, Wang Z, Tang WHW, Hazen SL (2017) Gut microbegenerated trimethylamine $\mathrm{N}$-oxide from dietary choline is prothrombotic in subjects. Circulation 135(17):1671-1673. https://doi.org/10.1161/CIRCULATIONAHA.116.025338

93. Wang Z, Klipfell E, Bennett BJ et al (2011) Gut flora metabolism of phosphatidylcholine promotes cardiovascular disease. Nature 472(7341):57-63. https://doi.org/10.1038/nature09922

94. Chen ML, Zhu XH, Ran L, Lang HD, Yi L, Mi MT (2017) Trimethylamine-N-oxide induces vascular inflammation by activating the NLRP3 inflammasome through the SIRT3-SOD2mtROS signaling pathway. J Am Heart Assoc 6(9):e006347. https://doi.org/10.1161/JAHA.117.006347

95. Sun X, Jiao X, Ma Y et al (2016) Trimethylamine N-oxide induces inflammation and endothelial dysfunction in human umbilical vein endothelial cells via activating ROS-TXNIP-NLRP3 inflammasome. Biochem Biophys Res Commun 481(1-2):6370. https://doi.org/10.1016/j.bbrc.2016.11.017

96. Chen S, Henderson A, Petriello MC et al (2019) Trimethylamine $\mathrm{N}$-oxide binds and activates PERK to promote metabolic dysfunction. Cell Metab 30(6):1141-1151. https://doi.org/10.1016/j.cmet. 2019.08.021

97. Zhuang R, Ge X, Han L et al (2019) Gut microbe-generated metabolite trimethylamine $\mathrm{N}$-oxide and the risk of diabetes: a systematic review and dose-response meta-analysis. Obes Rev 20(6):883-894. https://doi.org/10.1111/obr.12843

98. Koh A, Molinaro A, Stahlman M et al (2018) Microbially produced imidazole propionate impairs insulin signaling through mTORC1. Cell 175(4):947-961. https://doi.org/10.1016/j.cell. 2018.09.055

99. Brial F, Alzaid F, Sonomura K et al (2020) The natural metabolite 4-cresol improves glucose homeostasis and enhances $\beta$-cell function. Cell Rep 30(7):2306-2320. https://doi.org/10.1016/j.celrep. 2020.01.066

100. Wang P, Alvarez-Perez JC, Felsenfeld DP et al (2015) A highthroughput chemical screen reveals that harmine-mediated inhibition of DYRK1A increases human pancreatic beta cell replication. Nat Med 21(4):383-388. https://doi.org/10.1038/nm.3820

101. Kishino S, Takeuchi M, Park SB et al (2013) Polyunsaturated fatty acid saturation by gut lactic acid bacteria affecting host lipid composition. Proc Natl Acad Sci U S A 110(44):17808-17813. https://doi.org/10.1073/pnas.1312937110

102. Sonnweber T, Pizzini A, Nairz M, Weiss G, Tancevski I (2018) Arachidonic acid metabolites in cardiovascular and metabolic diseases. Int J Mol Sci 19(11):3285. https://doi.org/10.3390/ ijms19113285

103. Gaullier JM, Halse J, Hoivik HO et al (2007) Six months supplementation with conjugated linoleic acid induces regional-specific fat mass decreases in overweight and obese. Br J Nutr 97(3):550 560. https://doi.org/10.1017/S0007114507381324

104. Ahmad TR, Haeusler RA (2019) Bile acids in glucose metabolism and insulin signalling - mechanisms and research needs. Nat Rev Endocrinol 15(12):701-712. https://doi.org/10.1038/s41574-0190266-7

105. Midtvedt T (1974) Microbial bile acid transformation. Am J Clin Nutr 27(11):1341-1347. https://doi.org/10.1093/ajcn/27.11.1341 
106. Sayin SI, Wahlstrom A, Felin J et al (2013) Gut microbiota regulates bile acid metabolism by reducing the levels of tauro-betamuricholic acid, a naturally occurring FXR antagonist. Cell Metab 17(2):225-235. https://doi.org/10.1016/j.cmet.2013.01. 003

107. Thomas C, Gioiello A, Noriega L et al (2009) TGR5-mediated bile acid sensing controls glucose homeostasis. Cell Metab 10(3): 167-177. https://doi.org/10.1016/j.cmet.2009.08.001

108. Perino A, Pols TW, Nomura M, Stein S, Pellicciari R, Schoonjans $\mathrm{K}$ (2014) TGR5 reduces macrophage migration through mTORinduced $\mathrm{C} / \mathrm{EBP} \beta$ differential translation. J Clin Invest 124(12): 5424-5436. https://doi.org/10.1172/JCI76289

109. Velazquez-Villegas LA, Perino A, Lemos V et al (2018) TGR5 signalling promotes mitochondrial fission and beige remodelling of white adipose tissue. Nat Commun 9(1):245. https://doi.org/10. 1038/s41467-017-02068-0

110. Watanabe M, Houten SM, Mataki C et al (2006) Bile acids induce energy expenditure by promoting intracellular thyroid hormone activation. Nature 439(7075):484-489. https://doi.org/10.1038/ nature 04330

111. Fang S, Suh JM, Reilly SM et al (2015) Intestinal FXR agonism promotes adipose tissue browning and reduces obesity and insulin resistance. Nat Med 21(2):159-165. https://doi.org/10.1038/nm. 3760

112. Zhang Y, Lee FY, Barrera G et al (2006) Activation of the nuclear receptor FXR improves hyperglycemia and hyperlipidemia in diabetic mice. Proc Natl Acad Sci U S A 103(4):1006-1011. https://doi.org/10.1073/pnas.0506982103

113. Jiang C, Xie C, Lv Y et al (2015) Intestine-selective farnesoid X receptor inhibition improves obesity-related metabolic dysfunction. Nat Commun 6:10166. https://doi.org/10.1038/ ncomms 10166

114. Li F, Jiang C, Krausz KW et al (2013) Microbiome remodelling leads to inhibition of intestinal farnesoid $\mathrm{X}$ receptor signalling and decreased obesity. Nat Commun 4:2384. https://doi.org/10.1038/ ncomms 3384

115. Xie C, Jiang C, Shi J et al (2017) An intestinal farnesoid X receptor-ceramide signaling axis modulates hepatic gluconeogenesis in mice. Diabetes 66(3):613-626. https://doi.org/10.2337/ db16-0663

116. Attaye I, Pinto-Sietsma SJ, Herrema H, Nieuwdorp M (2020) A crucial role for diet in the relationship between gut microbiota and cardiometabolic disease. Annu Rev Med 71:149-161. https://doi. org/10.1146/annurev-med-062218-023720

117. Walker AW, Ince J, Duncan SH et al (2011) Dominant and dietresponsive groups of bacteria within the human colonic microbiota. ISME J 5(2):220-230. https://doi.org/10.1038/ismej.2010. 118

118. Kovatcheva-Datchary P, Nilsson A, Akrami R et al (2015) Dietary fiber-induced improvement in glucose metabolism is associated with increased abundance of Prevotella. Cell Metab 22(6):971982. https://doi.org/10.1016/j.cmet.2015.10.001

119. Zeevi D, Korem T, Zmora N et al (2015) Personalized nutrition by prediction of glycemic responses. Cell 163(5):1079-1094. https:// doi.org/10.1016/j.cell.2015.11.001

120. Zhao L, Zhang F, Ding X et al (2018) Gut bacteria selectively promoted by dietary fibers alleviate type 2 diabetes. Science 359(6380):1151-1156. https://doi.org/10.1126/science.aao5774

121. Chambers ES, Viardot A, Psichas A et al (2015) Effects of targeted delivery of propionate to the human colon on appetite regulation, body weight maintenance and adiposity in overweight adults. Gut 64(11):1744-1754. https://doi.org/10.1136/gutjnl2014-307913
122. van der Beek CM, Canfora EE, Lenaerts K et al (2016) Distal, not proximal, colonic acetate infusions promote fat oxidation and improve metabolic markers in overweight/obese men. Clin Sci 130(22):2073-2082. https://doi.org/10.1042/CS20160263

123. Bouter K, Bakker GJ, Levin E et al (2018) Differential metabolic effects of oral butyrate treatment in lean versus metabolic syndrome subjects. Clin Transl Gastroenterol 9(5):155. https:// doi.org/10.1038/s41424-018-0025-4

124. Boets E, Gomand SV, Deroover L et al (2017) Systemic availability and metabolism of colonic-derived short-chain fatty acids in healthy subjects: a stable isotope study. J Physiol 595(2):541-555. https://doi.org/10.1113/JP272613

125. McOrist AL, Miller RB, Bird AR et al (2011) Fecal butyrate levels vary widely among individuals but are usually increased by a diet high in resistant starch. J Nutr 141(5):883-889. https://doi.org/10. 3945/jn.110.128504

126. Baxter NT, Schmidt AW, Venkataraman A, Kim KS, Waldron C, Schmidt TM (2019) Dynamics of human gut microbiota and short-chain fatty acids in response to dietary interventions with three fermentable fibers. mBio 10(1):e02566-18. https://doi.org/ 10.1128/mBio.02566-18

127. Zhang Y, Zheng X, Huang F et al (2019) Ursodeoxycholic acid alters bile acid and fatty acid profiles in a mouse model of dietinduced obesity. Front Pharmacol 10:842. https://doi.org/10.3389/ fphar.2019.00842

128. Younossi ZM, Ratziu V, Loomba R et al (2019) Obeticholic acid for the treatment of non-alcoholic steatohepatitis: interim analysis from a multicentre, randomised, placebo-controlled phase 3 trial. Lancet 394(10215):2184-2196. https://doi.org/10.1016/S01406736(19)33041-7

129. Wortelboer K, Nieuwdorp M, Herrema H (2019) Fecal microbiota transplantation beyond Clostridioides difficile infections. EBioMedicine 44:716-729. https://doi.org/10.1016/j.ebiom. 2019.05.066

130. Gilijamse PW, Hartstra AV, Levin E et al (2020) Treatment with Anaerobutyricum soehngenii: a pilot study of safety and doseresponse effects on glucose metabolism in human subjects with metabolic syndrome. NPJ Biofilms Microbiomes 6(1):16. https:// doi.org/10.1038/s41522-020-0127-0

131. Depommier C, Everard A, Druart C et al (2019) Supplementation with Akkermansia muciniphila in overweight and obese human volunteers: a proof-of-concept exploratory study. Nat Med 25(7):1096-1103. https://doi.org/10.1038/s41591-019-0495-2

132. Tang C, Ahmed K, Gille A et al (2015) Loss of FFA2 and FFA3 increases insulin secretion and improves glucose tolerance in type 2 diabetes. Nat Med 21(2):173-177. https://doi.org/10.1038/nm. 3779

133. Fangmann D, Theismann EM, Turk K et al (2018) Targeted microbiome intervention by microencapsulated delayed-release niacin beneficially affects insulin sensitivity in humans. Diabetes Care 41(3):398-405. https://doi.org/10.2337/dc17-1967

134. Tunaru S, Kero J, Schaub A et al (2003) PUMA-G and HM74 are receptors for nicotinic acid and mediate its anti-lipolytic effect. Nat Med 9(3):352-355. https://doi.org/10.1038/nm824

135. Itoh Y, Kawamata Y, Harada M et al (2003) Free fatty acids regulate insulin secretion from pancreatic beta cells through GPR40. Nature 422(6928):173-176. https://doi.org/10.1038/ nature 01478

136. Hirasawa A, Tsumaya $\mathrm{K}$, Awaji $\mathrm{T}$ et al (2005) Free fatty acids regulate gut incretin glucagon-like peptide-1 secretion through GPR120. Nat Med 11(1):90-94. https://doi.org/10.1038/nm1168

137. Ichimura A, Hirasawa A, Poulain-Godefroy O et al (2012) Dysfunction of lipid sensor GPR120 leads to obesity in both 
mouse and human. Nature 483(7389):350-354. https://doi.org/10. 1038/nature10798

138. Agudelo LZ, Ferreira DMS, Cervenka I et al (2018) Kynurenic acid and Gpr35 regulate adipose tissue energy homeostasis and inflammation. Cell Metab 27(2):378-392. https://doi.org/10.1016/ j.cmet.2018.01.004

139. Rojas IY, Moyer BJ, Ringelberg CS, Tomlinson CR (2020) Reversal of obesity and liver steatosis in mice via inhibition of aryl hydrocarbon receptor and altered gene expression of CYP1B1, PPAR $\alpha$, SCD1, and osteopontin. Int J Obes 44(4): 948-963. https://doi.org/10.1038/s41366-019-0512-z
140. Makishima M, Okamoto AY, Repa JJ et al (1999) Identification of a nuclear receptor for bile acids. Science 284(5418):1362-1365. https://doi.org/10.1126/science.284.5418.1362

141. Cariou B, van Harmelen K, Duran-Sandoval D et al (2005) Transient impairment of the adaptive response to fasting in FXR-deficient mice. FEBS Lett 579(19):4076-4080. https://doi. org/10.1016/j.febslet.2005.06.033

Publisher's note Springer Nature remains neutral with regard to jurisdictional claims in published maps and institutional affiliations. 